\title{
Микроэлементный состав рассолов кимберлитовой трубки «Удачная» (Сибирская платформа)
}

\author{
Новиков Д.А. ${ }^{1,2}$, Ильин А.В. ${ }^{3}$, Черных А.В. ${ }^{1}$, Дульцев Ф.Ф. ${ }^{1}$ \\ ${ }^{1}$ Институт нефтегазовой геологии и геофизики им. А.А. Трофимука СО РАН, Новосибирск, \\ NovikovDA@ipgg.sbras.ru \\ ${ }^{2}$ Новосибирский начиональный исследовательский государственный университет, Новосибирск \\ ${ }^{3}$ Вилюйская геологоразведочная экспедичия АК «АЛРОСА» (ПАО), Удачный
}

\begin{abstract}
Аннотация. Приводятся результаты детальных исследований по распределению микроэлементов в кембрийских рассолах кимберлитовой трубки «Удачная», расположенной в центральной части Сибирской платформы. Изученные рассолы имеют хлоридный кальциевый, кальциево-натриевый, кальциево-магниевый и кальциево-магниево-натриевый состав с величиной общей минерализации от 94.4 до 391.3 г/дм³. В микроэлементном составе доминируют бром (до $3103.2 \mathrm{мг} /$ дм³ $^{3}$ ), сера (до $1282.2 \mathrm{мг} /$ дм³ $^{3}$ ), стронций (до $1058.7 \mathrm{мг/дм³)}$ и литий (до 23.7 мг/дм³). Установлены высокие концентрации Fe, Li, B, I, Si, Mn, Se и Rb. Рассчитанные коэффициенты водной миграции химических элементов в рассолах фонового состава выстроились следующим образом в порядке убывания: очень сильная интенсивность миграции $\mathrm{Br}_{1413}>\mathrm{Se}_{95}>\mathrm{I}_{72}>\mathrm{Li}_{20}>$ сильная $>\mathrm{B}_{7.33}$ $>\mathrm{Sr}_{7.31}>\mathrm{Hg}_{3.2}>$ средняя $\mathrm{Rb}_{0.75}>\mathrm{Ag}_{0.72}>\mathrm{Cs}_{0.13}>$ слабая $\mathrm{As}_{0.096}>\mathrm{Bi}_{0.092}>\mathrm{In}_{0.060}>\mathrm{Fe}_{0.039}>\mathrm{Mn}_{0.038}>$ очень слабая (инертная) интенсивность миграции $\mathrm{Ba}_{0.009}>\mathrm{P}_{0.006}>\mathrm{Ga}_{0.0011}>\mathrm{Si}_{0.0010}>\mathrm{Al}_{0.00004}>\mathrm{Zr}_{0.00002}$.

Ключевые слова: рассол, микроэлементы, кембрий, кимберлитовая трубка «Удачная», Сибирская платформа.

\section{The microelement composition of the "Udachnaya" kimberlite pipe brines (Siberian platform)}

\author{
Novikov D.A. ${ }^{1,2}$, Ilyin A.V. ${ }^{3}$, Chernykh A.V. ${ }^{1}$, Dultsev F.F. ${ }^{1}$ \\ ${ }^{1}$ Federal State Budgetary Scientific Institution Trofimuk Institute of Petroleum Geology and Geophysics of SB of RAS. \\ NovikovDA@ipgg.sbras.ru \\ ${ }^{2}$ Novosibirsk State University \\ ${ }^{3}$ Vilyui exploration expedition of PJSC ALROSA, Udachny
}

\begin{abstract}
Results of detailed investigation into the distribution of microelements in the Cambrian brines of the Udachnaya kimberlite pipe situated in the central part of the Siberian Platform are reported. The studied brines have calcium, calcium-sodium, calcium-magnesium and calcium-magnesium-sodium chloride composition with total mineralization 94.4 to $391.3 \mathrm{~g} / \mathrm{dm}^{3}$. The elements dominating in microelement composition are bromine (up to 3103.2 $\mathrm{mg} / \mathrm{dm}^{3}$ ), sulphur (up to $1282.2 \mathrm{mg} / \mathrm{dm}^{3}$ ), strontium (up to $1058.7 \mathrm{mg} / \mathrm{dm}^{3}$ ) and lithium (up to $23.7 \mathrm{mg} / \mathrm{dm}^{3}$ ). High concentrations of $\mathrm{Fe}, \mathrm{Li}, \mathrm{B}, \mathrm{I}, \mathrm{Si}, \mathrm{Mn}, \mathrm{Se}$ and $\mathrm{Rb}$ were detected. The calculated values of water migration coefficients for chemical elements in the brines of background composition were ranged in the decreasing order as follows: very intense migration $\mathrm{Br}_{1413}>\mathrm{Se}_{95}>\mathrm{I}_{72}>\mathrm{Li}_{20}>$ intense $>\mathrm{B}_{7.33}>\mathrm{Sr}_{7.31}>\mathrm{Hg}_{3.2}>$ medium $\mathrm{Rb}_{0.75}>\mathrm{Ag}_{0.72}>\mathrm{Cs}_{0.13}>$ weak $\mathrm{As}_{0.096}>\mathrm{Bi}_{0.092}>$ $\mathrm{In}_{0.060}>\mathrm{Fe}_{0.039}>\mathrm{Mn}_{0.038}>$ very weak (inert) migration intensity $\mathrm{Ba}_{0.009}>\mathrm{P}_{0.006}>\mathrm{Ga}_{0.0011}>\mathrm{Si}_{0.0010}>\mathrm{Al}_{0.00004}>\mathrm{Zr}_{0.00002}$.
\end{abstract}

Key words: brine, microelements, Cambrian, Udachnaya kimberlite pipe, Siberian platform.

Рассолы Сибирской платформы в течение длительного времени рассматриваются как комплексное гидроминеральное сырье и зачастую называются «жидкие руды», в которых установлены уникальные концентрации брома, стронция, лития, рубидия и многих других элементов. Вопросы особенностей геохимии рассолов Сибирской платформы рассмотрены во множестве работ А.С. Анциферова, С.В. Алексеева, В.Т. Балобаева, Е.А. Баскова, М.Б. Букаты, В.И. Вожова, А.А. Дзюбы, И.К. Зайцева, Ю.И. Кустова, И.С. Ломоносова, С.В. Лысак, Е.В. Пиннекера, В.Г. Ткачук, Н.И. Толстихина, Н.Я. Тычино, С.Л. Шварцева и многих других. (Басков, 1977; Анциферов, 1989; Вожов, 2006; Букаты, 2009; Novikov, 2017, 2018, 2019; Алексеева и др., 2018).

Кимберлитовая трубка «Удачная» находится в Далдыно-Алакитском алмазоносном районе Западно-Якутской алмазоносной провинции на правобережье среднего течения р. Далдын. Терри- 


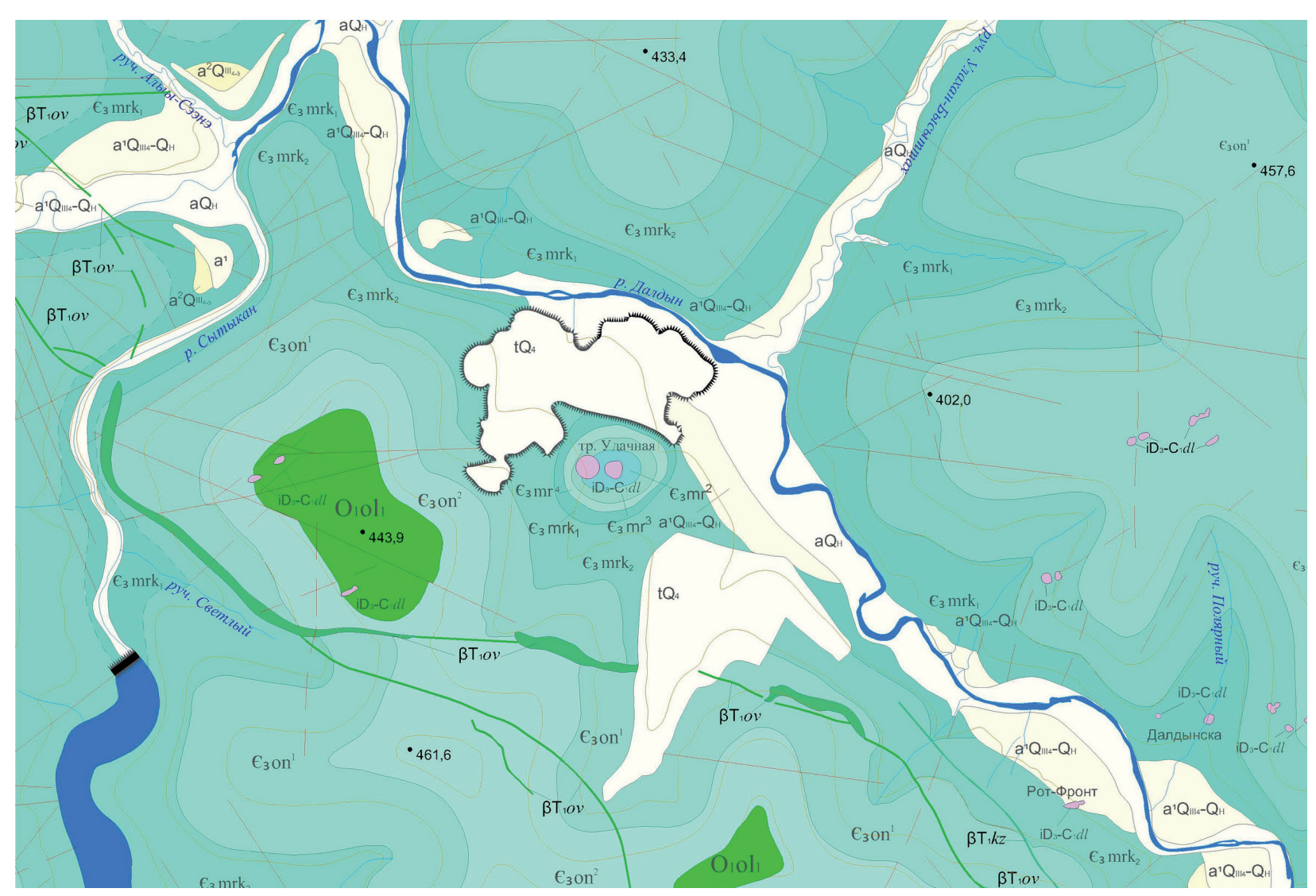

Рис. 1. Местоположение кимберлитовой трубки «Удачная».

Fig. 1. Location of the Udachnaya kimberlite pipe.

тория Далдынского кимберлитового поля приурочена к области сопряжения юго-западного склона Анабаро-Оленёкской антеклизы и северо-восточного борта Тунгусской синеклизы (рис. 1) (Мерзлотно..., 1984; Легостаева и др., 2018). Это крупнейшее по размерам рудного тела месторождение алмазов в России находится в 20 км от Северного полярного круга в Якутской алмазоносной провинции. Открытая разработка алмазоносной трубки Удачная осуществлялась с 1971 г. до июня 2014 г., глубина карьера достигла 640 м, а в настоящее время добыча алмазов продолжается подземным способом. Как в карьере, так и в подземном руднике отработка месторождения осложнена притоком хлоридных подземных рассолов в шахту на глубине свыше 700 м (-365...-465 м абс.) (Алексеев и др., 2018).

Гидрогеологические условия кимберлитовой трубки «Удачная» и района в целом изучались в несколько этапов в соответствии с общим ходом геологоразведочных работ. Первые сведения о гидрогеологических условиях месторождения алмазов тр. «Удачная» были получены в процессе разведочных работ 1956-1960 гг. Была охарактеризована только первая обводненная зона кимберлитов, которая классифицировалась как первый подмерзлотный водоносный горизонт. Гидрогеологические исследования заключались в определении мощности многолетнемерзлых пород, фиксации пьезометрического уровня подземных вод первого подмерзлотного водоносного горизонта и отбора подземных вод на полный химический анализ. Кроме того, в этот период выполнялись инженерногеологические и геокриологические исследования под технологические объекты. Согласно гидрогеологическому районированию, кимберлитовая трубка «Удачная» расположена в пределах Оленекского артезианского бассейна в северо-восточной части Сибирской платформы. Вмещающие ее осадочные породы представлены преимущественно карбонатами - известняками песчанистыми и глинистыми, кавернозными доломитами, мергелями, встречаются и сульфатоносные породы. В геокриологическом отношении регион относится к области сплошного распространения многолетнемерзлых пород, с криолитозоной уникальной мощности (более 1400 м) и низкой отрицательной температурой пород (до $-7.8^{\circ} \mathrm{C}$ на подошве слоя годовых теплооборотов). Особенностью ги- 


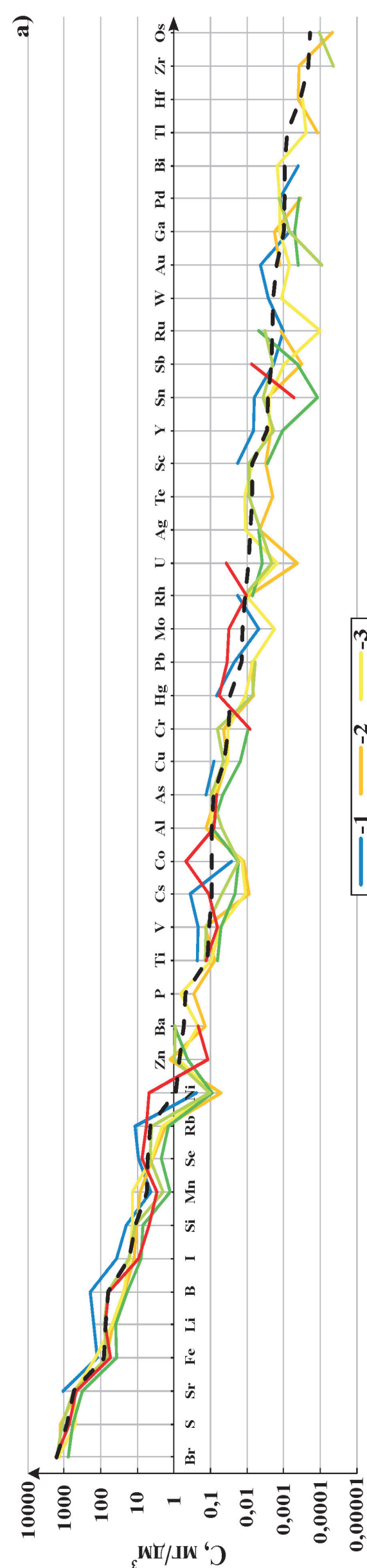

6
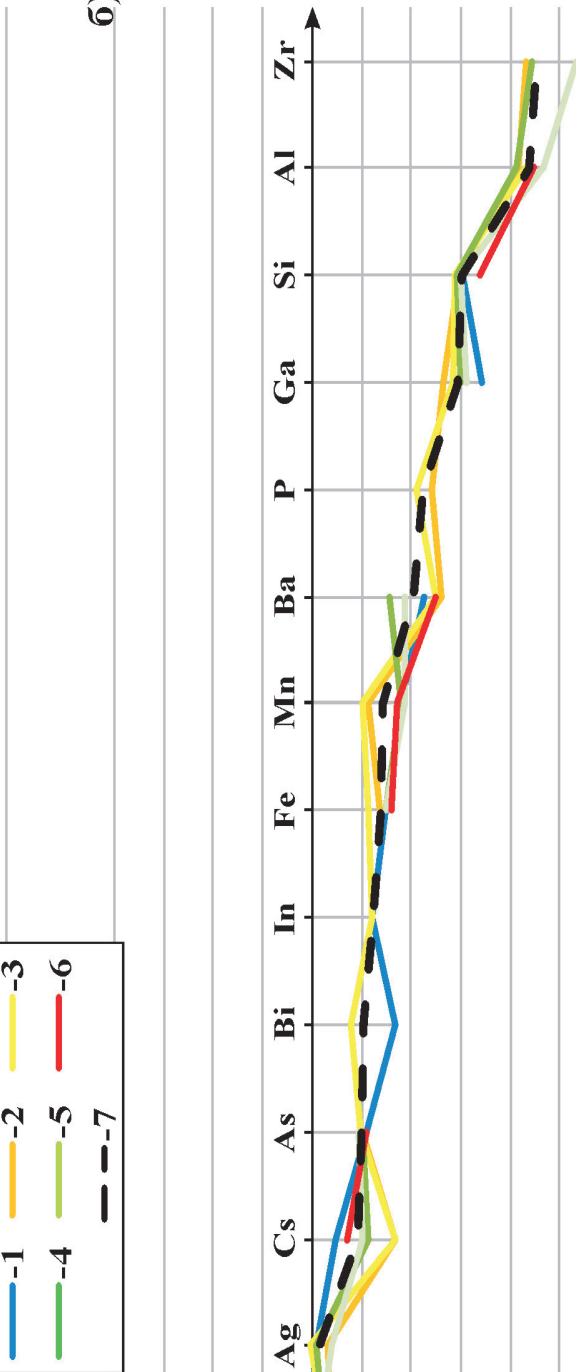

赵.
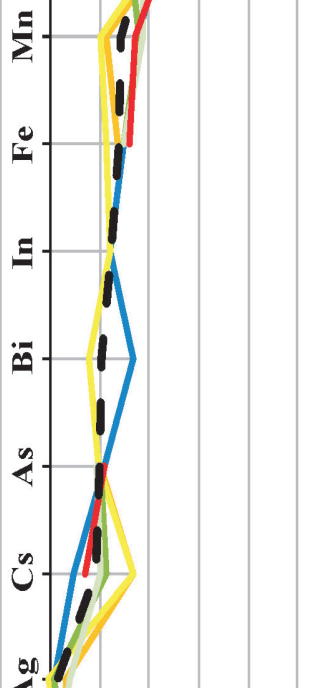

20.

$\hat{x}$

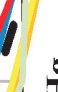

요
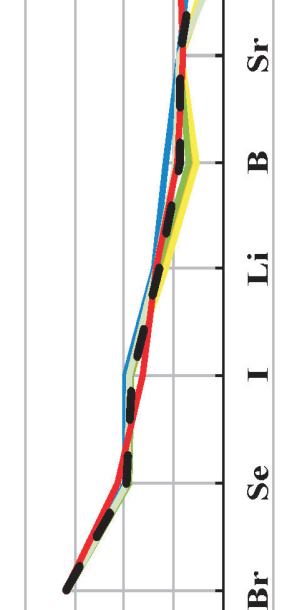

a

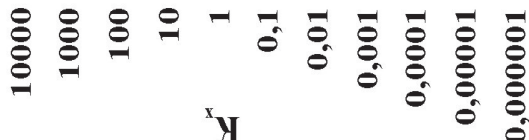

容

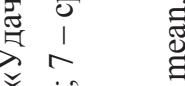

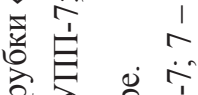

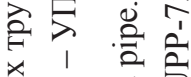

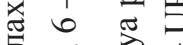

ठ을

त

ฉั

원

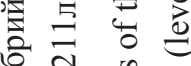

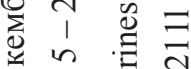

药

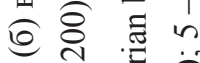

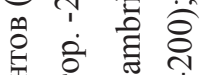

记

泉导

两.

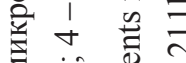

官

范

范

娄

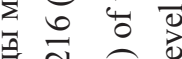

1 ê

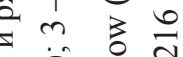

ङ ठิ

ते .

일

造

药

के त $\overline{0}$

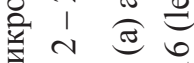

$\ddot{\overline{0}} \bar{\tau}$

ta

蔼

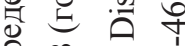

家 $\infty$ i

范 它

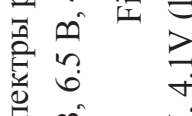

ปै

i i

岂 ते

I

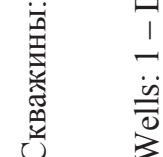


дрогеологического разреза является наличие межмерзлотных и подмерзлотных криопэгов хлоридного кальциевого состава с минерализацией до 425 г/дм³, залегающих на глубине 110-1000 м (Алексеев, 2009; Алексеев и др., 2018).

Сложность в эксплуатации крупнейших алмазоносных трубок Западной Якутии - это обводнённость рассолами из подмерзлотных высоконапорных водоносных горизонтов. С подобными проблемами сталкиваются при разработке кимберлитовых трубок «Екати» и «Диавик» в Канаде (Drever, 1997; Evangelou, Zhang, 2005; Jambor et al., 2002; Pfeifer, 1997). Состав подземных вод, объёмы их притоков к горным выработкам создают проблемы для ведения горно-геологических и добычных работ, влияют на производительность, сложность при утилизации и захоронении дренажных рассолов, оказывают воздействие на геоэкологическую ситуацию в районах разработки (Легостаева и др., 2018).

В основу данной работы легли результаты исследований проб рассолов, отобранных во время полевых работ в марте, апреле и июне 2019 г. Аналитические работы по изучению макро-, микроэлементного (включая редкие земли - РЗЭ) состава методами ICP-AES и ICP-MS были выполнены в Национальном исследовательском Томском политехническом университете. Изученные воды имеют интересный спектр распределения микроэлементов. Средние концентрации кембрийских рассолов скважин ДС - 4.2B, 6.5B, 4.1В (горизонт -465), 216л (горизонты -230 и -280), 211л (горизонты -200 и -250) и камеры УПП-7 приведены на рис. 2 а. Среди них, наиболее высокие содержания (при значениях фона более 100 мг/дм³) отмечаются у (мг/дм³): $\mathrm{Br}$ - от 798.4 до 3103.2; $\mathrm{S}$ - 491.9-1282.2; $\mathrm{Sr}$ - 314.9-1058.7. Вторая группа микроэлементов ( $\mathrm{Fe}, \mathrm{Li}, \mathrm{B}, \mathrm{I}, \mathrm{Si}, \mathrm{Mn}, \mathrm{Se}, \mathrm{Rb})$ характеризуются фоновыми концентрациями в растворе от 1 до 100 мг/дм³. Третья группа ( $\mathrm{Ni}, \mathrm{Zn}, \mathrm{Ba}, \mathrm{P}, \mathrm{Ti}, \mathrm{V}, \mathrm{Cs}, \mathrm{Co}, \mathrm{Al}$, $\mathrm{As}, \mathrm{Cu}, \mathrm{Cr}, \mathrm{Hg}, \mathrm{Pb}, \mathrm{Mo}, \mathrm{Rh}$ ) объединяет элементы с фоновыми содержаниями от 0.01 до 1 мг/дм³ и четвертая (U, Ag, Te, Sc, Y, Sn, Sb, Ru, W, Au, Ga, Pd, Bi, Tl, Hf, Zr, Os) соответствует фоновым концентрациям ниже 0.01 мг/дм³. С ростом общей минерализации в растворе накапливается ряд микроэлементов (Br, Sr, Fe, Li, B, I, Si, Se, Rb, Ti, V, Cs, Co, As, Cu, Hg, Pb, Rh, Ag, Sc, Y, Sn, Au, Pd, Tl), a поведение $\mathrm{S}, \mathrm{Mn}, \mathrm{Ni}, \mathrm{Zn}, \mathrm{Ba}, \mathrm{Al}, \mathrm{Cr}, \mathrm{Hg}, \mathrm{Pb}, \mathrm{U}, \mathrm{Sb}, \mathrm{Ru}$ и Ga носит более сложный характер.

Среди геологических факторов литолого-минералогические особенности водовмещающих пород выступают основными при протекании процессов формирования химического состава природных вод. А.И. Перельманом (Перельман, 1975) был предложен метод оценки водной миграции химических элементов в зоне гипергенеза по коэффициенту $\left(\mathrm{K}_{\mathrm{x}}\right)$, который определяется как отношение содержания химического элемента в минеральном остатке воды к его содержанию в водовмещающих породах или кларку литосферы. Этот коэффициент отражает интенсивность водной миграции, определяемую свойствами самого элемента, а также степень его концентрирования или рассеяния в природных водах. Нами для расчетов были использованы средние содержания химических элементов в карбонатных породах (Григорьев, 2009). Рассчитанные коэффициенты водной миграции химических элементов в водах фонового состава выстроились следующим образом в порядке убывания: очень сильная интенсивность миграции $\mathrm{Br}_{1413}>\mathrm{Se}_{95}>\mathrm{I}_{72}>\operatorname{Li}_{20}>$ сильная $>\mathrm{B}_{7.33}>\mathrm{Sr}_{7.31}$ $>\mathrm{Hg}_{3.2}>$ средняя $\mathrm{Rb}_{0.75}>\mathrm{Ag}_{0.72}>\mathrm{Cs}_{0.13}>$ слабая $\mathrm{As}_{0.096}>\mathrm{Bi}_{0.092}>\mathrm{In}_{0.060}>\mathrm{Fe}_{0.039}>\mathrm{Mn}_{0.038}>$ очень слабая (инертная) интенсивность миграции $\mathrm{Ba}_{0.009}>\mathrm{P}_{0.006}>\mathrm{Ga}_{0.0011}>\mathrm{Si}_{0.0010}>\mathrm{Al}_{0.00004}>\mathrm{Zr}_{0.00002}$. Ряды миграции элементов в кембрийских рассолах трубки Удачная приведены на рисунке 2 б.

Установлены некоторые особенности поведения элементов в изученных рассолах по сравнению с классической схемой А.И. Перельмана (Основы..., 1982). Так, бор перешел в класс элементов, обладающих сильной миграционной способностью, рубидий - в класс средней, мышьяк, марганец, барий, фосфор и кремний - в класс слабой и очень слабой. При этом селен и литий передвинулись в класс элементов с очень сильной миграционной способностью. Не рассмотренные А.И. Перельманом элементы, например, $\mathrm{Hg}$ вошла в группу элементов, обладающих сильной миграционной способностью; Ag в группу средней и $\mathrm{Bi}$, In и $\mathrm{Ga}$ - в группу очень слабой (см. рис. 2 б). Кларк концентрации элементов в карбонатных породах относительно пород земной коры может объяснить наблюдаемые сдвиги в группах по интенсивности водной миграции, но этот вопрос требует отдельного изучения. 
Исследования проводились при финансовой поддержке проектов ФНИ № 0331-2019-0025 «Геохимия, генезис и механизмы формирования состава подземных вод арктических районов осадочных бассейнов Сибири» и РФФИ № 18-05-70074 «Ресурсы Арктики».

\section{Литература}

1. Алексеев С.В. Криогидрогеологические системы Якутской алмазоносной провинции. Новосибирск. Изд-во: ГЕО. 2009. 319 с.

2. Алексеев С.В., Алексеева Л.П., Гладков А.С., Трифонов Н.С., Серебряков Е.В., Павлов С.С., Ильин А.В. Рассолы глубоких горизонтов кимберлитовой трубки Удачная // Геодинамика и тектонофизика. 2018. T. 9. № 4. C. 1235-1253. DOI: 10.5800/GT-2018-9-4-0393.

3. Алексеева Л.П., Алексеев С.В. Геохимия подземных льдов, соленых вод и рассолов криоартезианских бассейнов северо-востока Сибирской платформы // Геология и геофизика. 2018. Т. 59. № 2. С. 183-197.

4. Анциферов А.С. Гидрогеология древнейших толщ Сибирской платформы. М. Изд-во: Недра. 1989. 176 с.

5. Басков Е.А. Минеральные воды и палеогидрогеология Сибирской платформы. Труды ВСЕГЕИ. Новая серия. Т. 254. М. Изд-во: Недра. 1977. 148 с.

6. Букаты М.Б. Гидрогеологическое строение западной части Сибирской платформы (в связи с поисками, разведкой и разработкой месторождений нефти и газа) // Геология и геофизика. 2009. Т. 50. № 11. C. 1201-1217.

7. Вожов В.И. Подземные воды и гидроминеральное сырье Лено-Тунгусской нефтегазоносной провинции. Новосибирск: СНИИГГиМС. 2006. 209 с.

8. Григорьев Н.А. Распределение химических элементов в верхней части континентальной коры. Екатеринбург. Изд-во: УрО РАН. 2009. 383 с.

9. Легостаева Я.Б., Попов В.Ф., Ксенофонтова М.И. Гидрогеологические условия и геоэкологическая ситуация на территории подземных техногенных хранилищ при утилизации дренажных рассолов Удачнинского горно-обогатительного комбината // Отечественная геология. 2018. № 3. С. 93-102. DOI: $10.24411 / 0869-7175-2018-10021$.

10. Мерзлотно-гидрогеологические условия Восточной Сибири (под ред. П.И. Мельникова). Новосибирск. Изд-во: Наука. 1984. 192 с.

11. Основы гидрогеологии. Гидрогеохимия (гл. ред. С.Л. Шварцев). Новосибирск. Изд-во: Наука. 1982. 287 с.

12. Перельман А.И. Геохимия ландшафта. Изд. 2-е. М. Изд-во: Высшая школа. 1975. 342 с.

13. Drever J.I. The Chemistry of Natural Waters: Surface and Ground water Environments. Prentice-Hall Inc., 1997. $436 \mathrm{p}$.

14. Evangelou V.P., Zhang Y.L. A Review: Pyrite Oxidation Mechanisms and Acid Mine Drainage Prevention // Critical Reviews in Environmental Science and Technology. 2005. № 25(2). P. 141-199. DOI: $10.1080 / 10643389509388477$.

15. Jambor J.L., Dutrizac J.E., Groat L.A., Raudsepp M. Static Tests of Neutralization Potentials of Silicate and Aluminosilicate Minerals // Environmental Geology. 2002. № 43. P. 1-17. DOI: 10.1007/s00254-002-0615-y.

16. Novikov D.A. Hydrogeochemistry of the Arctic areas of Siberian petroleum basins // Petroleum Exploration and Development. 2017. V. 44. №5. P. 780-788. DOI: 10.1016/S1876-3804(17)30088-5.

17. Novikov D.A., Chernykh A.V., Dultsev F.F. Geochemistry of brines in Vendian deposits of the Siberian platform // IOP Conference Series: Earth and Environmental Science. 2018. V. 193. № 012052. DOI: $10.1088 / 1755-1315 / 193 / 1 / 012052$.

18. Novikov D.A., Zhitova L.M., Dultsev F.F., Chernykh A.V., Primary data on the impact from trap magmatism on the hydrogeochemistry of brines in the southwestern part of the Kureyka syncline (Siberian Platform) // E3S Web of Conferences. 2019. V. 98. № 08017. DOI: 10.1051/e3sconf/20199808017.

19. Pfeifer H.R. A Model for Fluids in Metamorphosed Ultramafic Rocks: Observations at Surface and Subsurface Conditions (High pH Spring Waters) // Schweizerische Mineralogische und Petrographische Mitteilungen. 1977. № 57. P. 361-396. 